\title{
Population Genetic Analysis of Tomato spotted wilt virus on Peanut in North Carolina and Virginia
}

\author{
A. C. Kaye, J. W. Moyer, E. J. Parks, I. Carbone, and M. A. Cubeta
}

Department of Plant Pathology, P.O. Box 7616, North Carolina State University, Raleigh 27695.

Accepted for publication 1 September 2010.

\begin{abstract}
Kaye, A. C., Moyer, J. W., Parks, E. J., Cargone, I., and Cubeta, M. A. 2011. Population genetic analysis of Tomato spotted wilt virus on peanut in North Carolina and Virginia. Phytopathology 101:147-153.

Exploring the genetic diversity and evolutionary history of plant viruses is critical to understanding their ecology and epidemiology. In this study, maximum-likelihood and population genetics-based methods were used to investigate the population structure, genetic diversity, and sources of genetic variation in field isolates of Tomato spotted wilt virus (TSWV) from peanut in North Carolina and Virginia. Selected regions of the nucleocapsid, movement, and RNA-dependent RNA polymerase genes were amplified and sequenced to identify haplotypes and infer genetic

haplotypes were associated with geographic area, peanut cultivar, or year of isolation. The population was panmictic at the regional level and high levels of genetic diversity were observed among isolates. There was evidence for positive selection on single amino acids in each gene on a background of predominant purifying selection acting upon each locus. The results of compatibility analyses and the persistence of specific gene sequences in isolates collected over three field seasons suggest that recombination was occurring in the population. Estimates of the population mutation rate suggest that mutation has had a significant effect on the shaping of this population and, together with purifying selection, these forces have been the predominant evolutionary forces influencing the TSWV population in peanut in North Carolina and Virginia.
\end{abstract} relationships between isolates of TSWV with heuristic methods. The haplotype structure of each locus consisted of 1 or 2 predominant haplotypes and $>100$ haplotypes represented by a single isolate. No specific
Additional keywords: population diversity.
Plant viruses are a significant barrier to optimal worldwide crop production and can cause severe economic losses to growers (62). Tomato spotted wilt virus (TSWV) can infect $>1,000$ species of plants (40) and has been estimated to cause annual losses of U.S. $\$ 1$ billion (1). Disease symptoms such as leaf spotting, stunting, and pod deformation associated with TSWV infection of peanut (Arachis hypogaea L.) have been observed in North Carolina and Virginia for $>15$ years (21). Yield losses to TSWV have varied over this period of time and have been significant periodically, making the virus a serious threat to the production of healthy peanut crops. The management of TSWV requires an integrated approach that involves cultural practices (such as planting date and rate of seeding), soil-applied insecticides, and resistant cultivars (13).

TSWV is a member of the genus Tospovirus that belongs to the family Bunyaviridae and represents the type member of the genus (34). The virus particle is quasispherical (80 to $120 \mathrm{~nm}$ in diameter), with a lipid bilayer envelope that contains surface glycoproteins and a single-stranded RNA tripartite genome $(5,25,63)$. A $2 \cdot 9-\mathrm{kb}$ segment of the genome (S) encodes for a nonstructural protein (NSs), which is a suppressor of silencing, and the nucleocapsid $(\mathrm{N})$ protein $(15,57)$. A 4.8-kb segment of the genome (M) encodes a nonstructural protein $(\mathrm{NSm})$ that facilitates virus cell-to-cell movement and a precursor to the G1 and G2 external glycoproteins $(29,30,52,53)$. The large 8.9-kb segment of the genome (L) encodes for the RNA-dependent RNA polymerase (RdRp) associated with virus replication (2).

Using a multilocus approach, Tsompana and colleagues (59) analyzed genes from all three genomic segments to examine the

Corresponding author: A. C. Kaye; E-mail address: a_kaye@msn.com

doi:10.1094/PHYTO-01-10-0035

(C) 2011 The American Phytopathological Society population genetics of TSWV from 10 hosts on a global scale. Results from these pioneering studies suggested that populations of TSWV were differentiated geographically and that positive and purifying selections were acting on the three independent loci. Although the studies of Tsompana et al. (59) provided the first insight into the population genetics of TSWV from multiple hosts on a global scale, questions remained about the population genetics of TSWV sampled from a single host on a local geographic and temporal scale. This critical information could potentially be used to improve disease-management strategies, investigate the interactions between TSWV and host plant defenses, and generate statistical estimates of TSWV population genetics parameters for disease modeling and biological characterization.

The primary objective of this research was to perform a comprehensive assessment of the genetic diversity and structure of populations of TSWV sampled from symptomatic peanut leaflets in a geographic production area encompassing fields in North Carolina and Virginia over 3 years. To better elucidate the evolutionary processes underlying these populations, we examined three regions of the TSWV genome on different genomic segments. Given the propensity for TSWV to generate allelic diversity via mutation, genetic reassortment, or recombination (60), we hypothesized that field populations of TSWV from peanut would exhibit a high level of genetic diversity and have little to no geographic structure. The second objective of this study was to determine the relative contribution of different evolutionary processes to the genetic diversity and structure of field populations of TSWV in peanut on a local geographic scale. Our hypothesis was that mutation and purifying selection would be the major forces shaping localized population structure, consistent with reported trends in global populations (60), but that recombination would also be a strong factor, based on other plant virus studies (20). 


\section{MATERIALS AND METHODS}

Isolates. In total, 196 isolates of TSWV from peanut $(A$. hypogaea L.) leaves exhibiting typical symptoms (e.g., ring spots, "rusting", stunting, shortened internodes, and tip dieback) were used in this study (Table 1). A hierarchical sampling strategy was deployed to collect leaf samples from one field of peanut in Bertie County, $\mathrm{NC}\left(77.1755^{\circ} \mathrm{W}, 36.1324^{\circ} \mathrm{N}\right)$ in 2005 ; one field each in Bertie County, NC and Suffolk County, VA (76.6097 $\mathrm{W}$, $36.7411^{\circ} \mathrm{N}$ ) in 2006; and one field each in Bertie and Sampson Counties, NC $\left(78.3318^{\circ} \mathrm{W}, 34.8462^{\circ} \mathrm{N}\right)$ and Suffolk County, VA in 2007. Quadrifoliate leaves were collected every 4 weeks for 16 weeks from arbitrarily chosen symptomatic plants during each year. Each geographic area represented a different population in this study. All leaf samples were transported from the field to the laboratory on ice and were either processed for testing the same day or stored at $4{ }^{\circ} \mathrm{C}$ overnight. Each leaf sample was tested with either a double-antibody sandwich enzyme-linked immunosorbent assay (DAS-ELISA) or Immunostrip (Agdia, Elkhart, IL) to determine the presence of TSWV.

RNA extraction. Total plant RNA was extracted from each leaf sample with either TRIzol Reagent (Invitrogen Corporation, Carlsbad, CA), RNeasy Plant Mini Kit (Qiagen, Valencia, CA) with $1 \%$ polyvinyl pyrrolidine in Rneasy lysis buffer (RLT) buffer (49), or directly from leaf sap-saturated Immunostrips using the RNeasy Plant Mini Kit with 1\% polyvinyl pyrrolidine according to the manufacturer's protocol.

Reverse-transcription polymerase chain reaction and sequencing. Extracted RNA from each sample was used as a template for reverse-transcription polymerase chain reaction (RTPCR) to generate complementary DNA (cDNA) for selected regions of the nucleocapsid $(\mathrm{N})$, movement $(\mathrm{NSm})$, and $\mathrm{RdRp}$ genes of TSWV (59). A 720-bp fragment of the $\mathrm{N}$ gene was amplified with the S1976 forward primer (5'-ACAGCTG(ACT) TTTTAAGCAAGTTCTG-3') and the S2847 reverse primer (5'AAGAAACGACTGCGG(AG)ATACA-3'). A 699-bp fragment of the NSm gene was amplified with the M2 forward primer (5'GAGCAATCAGTGC(AG)TCAGA-3') and the M824 reverse primer (5'-CTTGCA(AG)GC(CT)TCAATGAATG-3'). A 999-bp fragment of the RdRp gene was obtained in two independent amplifications with the L7541 forward primer (5'-CTCTGATAA ATGATGCAT-3') and L8250 reverse primer ( $5^{\prime}$-(AG)GG(AG) CAATTGACATTCTT- $\left.3^{\prime}\right)$ and the L7109 forward primer (5'T(AG)AGGCT(CT)CCTGAAGTAGG-3') and L7750Y reverse primer (5'-ATGTGGCATATGT(CT)CTGC-3'). All oligonucleotide primers used in this study were synthesized by Integrated DNA Technologies, Inc. (Coralville, IA). cDNA was synthesized with AMV Reverse Transcriptase (Promega Corp., Madison, WI)

TABLE 1. Year of collection, geographic area, peanut cultivar, and number of amplified nucleocapsid (N), movement (NSm), and RNA-dependent RNA polymerase ( $\mathrm{RdRp}$ ) fragments of 196 isolates of Tomato spotted wilt virus

\begin{tabular}{|c|c|c|c|c|c|}
\hline \multirow[b]{2}{*}{ Year } & \multirow[b]{2}{*}{ Geographic area } & \multirow[b]{2}{*}{ Peanut cultivar } & \multicolumn{3}{|c|}{ Loci $^{\mathrm{a}}$} \\
\hline & & & $\mathrm{N}$ & NSm & $\operatorname{RdRp}$ \\
\hline \multirow[t]{3}{*}{2005} & Bertie County, NC & Brantley & 6 & 6 & 6 \\
\hline & $\ldots$ & $\mathrm{NC} 12 \mathrm{C}$ & 3 & 3 & 3 \\
\hline & $\ldots$ & Unknown & 13 & 12 & 10 \\
\hline \multirow[t]{3}{*}{2006} & Bertie County, NC & $\mathrm{NC} 12 \mathrm{C}$ & 22 & 22 & 17 \\
\hline & Suffolk County, VA & Gregory & 5 & 7 & 7 \\
\hline & $\ldots$ & Perry & 12 & 12 & 12 \\
\hline \multirow[t]{5}{*}{2007} & Bertie County, NC & Perry & 36 & 36 & 36 \\
\hline & $\ldots$ & $\mathrm{NC} 12 \mathrm{C}$ & 8 & 8 & 8 \\
\hline & Suffolk County, VA & $\mathrm{NC} 12 \mathrm{C}$ & 42 & 42 & 42 \\
\hline & Sampson County, NC & Gregory & 32 & 32 & 32 \\
\hline & $\ldots$ & NCV11 & 10 & 10 & 10 \\
\hline Total $^{\text {b }}$ & $\ldots$ & $\ldots$ & 189 & 190 & 183 \\
\hline
\end{tabular}

a Total number of gene sequences amplified from isolates used in this study.

b Total number of amplified genes for each locus. using the reverse primer and the method of Law and Moyer (31). PCR amplification was performed in a total volume of $25 \mu \mathrm{l}$ with $1 \times$ PCR buffer (Promega Corp.), $25 \mu \mathrm{M} \mathrm{MgCl}, 2.5 \mu \mathrm{M}$ dNTPs (Promega Corp.), GoTaq polymerase (Promega Corp.), and $10 \mu \mathrm{M}$ each forward and reverse primer for each locus with $2.5 \mu \mathrm{l}$ of cDNA. The cycles were $94^{\circ} \mathrm{C}$ for $10 \mathrm{~min}$, followed by 40 cycles of $94^{\circ} \mathrm{C}$ for $1 \mathrm{~min}, 55^{\circ} \mathrm{C}$ for $1 \mathrm{~min}, 72^{\circ} \mathrm{C}$ for $1 \mathrm{~min}$, and an extension at $72^{\circ} \mathrm{C}$ for $10 \mathrm{~min}$. Amplified DNA was subjected to electrophoresis in $1 \%$ agarose and visualized with UV transillumination. A $1 \mathrm{~kb}+$ ladder (Promega Corp.) was used to determine size of the amplified product. Amplified products were cleaned with either a QIAquick PCR Purification (Qiagen) or a PerfectPrep PCR Cleanup 96 Kit (Eppendorf, Germany) according to the manufacturer's protocol. Sequencing reactions were performed with $3730 x$ l DNA Analyzers (Applied Biosystems, Foster City, CA) using Big Dye chemistry (version 3) at the Duke University Institute for Genomic Sciences and Policy DNA Sequencing Facility (Durham, NC). Forward and reverse chromatograms were aligned using Sequencher (version 4.6; Gene Codes Corporation, Ann Arbor, MI) and with visual examination. All sequences for each locus were submitted to GenBank ( $\mathrm{N}$ accession numbers FJ234451 to FJ234639, NSm accession numbers FJ234640 to FJ234829, and RdRp accession numbers FJ261988 to FJ262170).

Haplotype and site compatibility analyses of cDNA sequences. A suite of nucleotide analysis programs, SNAP Workbench, was used in this study for population genetics analyses of the sequence data (44). Briefly, the sequences from each separate locus were aligned with ClustalW version 1.7 (58) and collapsed into haplotypes after removing insertions, deletions, and infinite sites violations with SNAP Map (4).

Site compatibility matrices for each locus or population were generated using SNAP Clade (6) on collapsed haplotype data. Compatibility matrices were graphically illustrated using SNAP Matrix (6) and Inkscape version 0.45.1. Matrices were examined for incompatible sites $(7,26)$, and these were removed from the dataset using SNAP CladeEx (6). The removal of incompatible sites is a prerequisite step needed for other analyses used in this study that assume no recombination in the data (3). The data set used for each analysis is indicated below as whole, using all of the sites, or compatible, with incompatible sites removed.

Neutrality and population subdivision. The population mutation rate, theta $\left(\theta_{\mathrm{W}}\right)$, was estimated from the number of segregating sites, $s$ (64), and $k$, the average pairwise distance between sequences (54) from individual whole sequences using DnaSP version 4.50 (48). DnaSP was used to estimate haplotype diversity (Hd) on collapsed whole data $(36,37)$. DnaSP was also used to calculate test statistics and $P$ values for individual sequences containing only compatible sites from each locus for Tajima's $D$ (55), Fu and Li's $F^{*}$ and $D^{*}$ without an outgroup (19), Fu's $F_{\text {s }}$ (18), and Wright's $F_{\mathrm{ST}}$, a measure of the proportion of the total genetic variance contained in a subpopulation relative to the total genetic variance. Values can range from 0 to 1.000 and values of $F_{\text {ST }}>0.05(5 \%)$ suggest a degree of differentiation among populations (67). The average number of pairwise differences per nonsynonymous site, $\mathrm{dN}$, the average number of pairwise differences per synonymous site, $\mathrm{dS}$, and their ratio, $\mathrm{dN} / \mathrm{dS}(\omega)$, were calculated for each locus using whole data sets, according to the counting method of Yang and Nielsen (70) as implemented in the YN00 program in PAML, version 4 (68). Codon-based analysis of positive selection for each locus was carried out on whole datasets, using the program codeml as implemented in PAML, version 4, with the Bayes empirical Bayes (BEB) approach (71).

To test for differentiation in the TSWV population, SNAP Map was used to generate files for Seqtomatrix, which converts sequence data into a distance matrix. The test PermtestK uses the molecular variation to test if two sampled localities are genetically different (23). Hudson's estimates of $K_{\mathrm{S}}, K_{\mathrm{T}}, K_{\mathrm{ST}}$, and $S_{\mathrm{nn}}$ 
were used to determine the presence of subdivision in populations $(22,23)$. The tests were performed on both whole and compatibleonly sequence data and the results were compared to identify possible recombination. PermtestK is powerful when sample sizes are small but it can be compromised when there are unequal sample sizes (23), whereas Hudson's $S_{\mathrm{nn}}$ is powerful at all sample sizes and diversities (22). A value of the $S_{\mathrm{nn}}$ statistic close to 1 indicates high subpopulation differentiation and a value $\leq 0.5$ indicates panmixia (22).

\section{RESULTS}

Haplotype analysis and site compatibility of cDNA sequences. In total, 2,418 nucleotides from the N, NSm, and RdRp genomic regions of TSWV were amplified for each isolate and collapsed into haplotypes (Table 2). The haplotype structure in each of the three loci consisted of 1 major haplotype, which contained the majority of isolates, and $>100$ minor haplotypes, frequently represented by a single isolate (singleton haplotype). In all, 150 haplotypes from 189 isolates were identified in the $\mathrm{N}$ gene, which had a haplotype diversity of $99.3 \%$; 151 haplotypes from 190 isolates were identified in the NSm gene, which had a haplotype diversity of $99.7 \%$; and 167 haplotypes from 183 isolates were identified in the $\mathrm{RdRp}$ gene, which had a haplotype diversity of $99.9 \%$. The largest major haplotype for each locus contained $8.5,6.8$, and $2.2 \%$ of all isolates of the N, NSm, and RdRp gene sequences, respectively. The NSm gene had the highest percentage, $29.4 \%$, of haplotypes that contained more than a single isolate and the RdRp gene had the lowest percentage, $14.7 \%$. The RdRp gene had 156 singleton haplotypes while the $\mathrm{N}$ gene and NSm genes had 135 singleton haplotypes each.

The specific isolate composition of each haplotype differed for each locus, with one exception: the only haplotype that maintained its exact isolate composition across all three loci consisted

TABLE 2. Summary of the number of isolates, length of gene fragment, haplotype number, haplotype diversity, and haplotype frequencies of the nucleocapsid $(\mathrm{N})$, movement (NSm), and RNA-dependent RNA polymerase (RdRp) loci of Tomato spotted wilt virus on peanut

\begin{tabular}{lcccccc}
\hline Gene & $n^{\mathrm{a}}$ & $\mathrm{L}^{\mathrm{b}}$ & $\mathrm{H}^{\mathrm{c}}$ & $\mathrm{Hd}^{\mathrm{d}}$ & $\mathrm{H}(\%)^{\mathrm{e}}$ & Singletons $^{\mathrm{f}}$ \\
\hline $\mathrm{N}$ & 189 & 720 & 150 & 0.993 & 29.1 & 135 \\
$\mathrm{NSm}$ & 190 & 699 & 151 & 0.997 & 29.4 & 135 \\
RdRp & 183 & 999 & 167 & 0.999 & 14.7 & 156
\end{tabular}

a Total number of isolates used for each locus.

$\mathrm{b}$ Total length of the sequence used for each locus.

c Total number of haplotypes collapsed in each locus.

d Measurement of haplotype diversity, $\hat{h}=n\left(1-\Sigma x_{i}^{2}\right) /(n-1)(36)$.

e Total percentage of isolates that collapsed into a haplotype containing more than one isolate.

${ }^{f}$ Total number of haplotypes that contained only a single isolate. of F22N7 and F40N7, two isolates from peanut cv. NC12C in Suffolk County, VA in 2007. Haplotypes that contained more than one isolate and a mixture of isolate characteristics, such as collection year and geographical area, were examined for patterns of association and frequency. The major haplotype for the $\mathrm{N}$ and NSm loci contained isolates from each year, geographic area, and several different cultivars. In contrast, the major haplotype for the $\mathrm{RdRp}$ locus contained only isolates that were sampled from symptomatic peanut plants in Bertie County in 2007. Further examination of the relevant minor haplotypes for each locus showed similar trends of diversity across isolate characteristics. Two of the minor haplotypes of the $\mathrm{N}$ locus and one minor haplotype of the NSm locus were collected in each collection year of the study. One haplotype of the N locus and two of the NSm locus were collected in each geographic area of the study. Three haplotypes of both the N and NSm loci were collected in at least three different cultivars during the study. In contrast, only one haplotype other than the major haplotype contained more than one cultivar or geographic area in the RdRp locus. All other haplotypes in all three loci that were not singletons were not distinguished by differences in year, geographic area, or cultivar.

The population statistics were determined for each locus and compared (Table 3). Nucleotide diversity was variable among the loci. The distances for the N and NSm were similar at 6.907 and 6.806, respectively, while the RdRp locus had the highest average pairwise distance of 13.035; this also serves as an estimate of the population mutation rate, $\theta$ (54). Watterson's estimates of average $\theta$ were approximately five times higher than Tajima's estimate for each locus. The genetic distances at nonsynonymous sites between isolates were highest in the NSm gene (0.003) but similar for the $\mathrm{N}$ and RdRp locus at 0.0015 and 0.0019 , respectively. The genetic distances at synonymous sites between isolates were highest in the RdRp gene (0.0471) but similar for the $\mathrm{N}$ and NSm at 0.0335 and 0.0303 , respectively. The values of the $\mathrm{dN} / \mathrm{dS}$ ratio, $\omega$, were $<1.0$ for each locus (70). Codon-based $\mathrm{BEB}$ analysis of selection found evidence of positive selection at amino acid site $222(\mathrm{~S} \rightarrow \mathrm{C})$ in the $\mathrm{N}$ gene, site $65(\mathrm{~L} \rightarrow \mathrm{F})$ in the $\mathrm{NSm}$, and site $32(\mathrm{Q} \rightarrow \mathrm{R}$ or $\mathrm{Q} \rightarrow \mathrm{K})$ in the $\mathrm{RdRp}$, with $P>99 \%$. The positively selected amino acid change in the $\mathrm{N}$ gene was present in 18 total isolates, of which 17 were isolates sampled from Perry, Gregory, NC12C, Brantley, and NC_V11 cultivars from all three geographic areas in 2007. The remaining isolate with the change was sampled in 2005 from Bertie County. The positively selected amino acid change that occurred in the NSm gene was present in a total of 73 isolates across all years, cultivars, and geographic areas, although half of the total mutations occurred in isolates sampled from 2007. The positively selected amino acid change that occurred in the RdRp gene was present in 18 isolates from 2007 and 1 isolate from 2005. The change from $\mathrm{Q}$ to $\mathrm{R}$ occurred in 17 of the 2007 isolates, across all cultivars and geographic areas, but the change from $\mathrm{Q}$ to $\mathrm{K}$

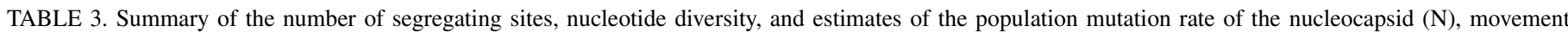
(NSm), and RNA-dependent RNA polymerase (RdRp) loci of Tomato spotted wilt virus on peanut

\begin{tabular}{|c|c|c|c|c|c|c|c|c|c|c|c|}
\hline Gene & $s^{\mathrm{a}}$ & $k^{\mathrm{b}}$ & $\pi^{\mathrm{c}}$ & $\mathrm{nN}^{\mathrm{d}}$ & $\mathrm{dN}^{\mathrm{e}}$ & $n S^{f}$ & $\mathrm{dS}^{\mathrm{g}}$ & $\omega^{\mathrm{h}}$ & Selected sites ${ }^{i}$ & $\theta_{W^{j}}$ & $\theta_{\mathrm{W}} /$ site \\
\hline $\mathrm{N}$ & 176 & 6.907 & 0.010 & 565 & 0.0015 & 155 & 0.0335 & 0.045 & $222, \mathrm{~S} \rightarrow \mathrm{C}$ & 30.26 & 0.042 \\
\hline NSm & 214 & 6.806 & 0.010 & 546 & 0.0030 & 153 & 0.0303 & 0.099 & $65, \mathrm{~L} \rightarrow \mathrm{F}$ & 36.76 & 0.053 \\
\hline $\mathrm{RdRp}$ & 335 & 13.035 & 0.013 & 794 & 0.0019 & 205 & 0.0471 & 0.039 & $32, \mathrm{Q} \rightarrow \mathrm{R}, \mathrm{Q} \rightarrow \mathrm{K}$ & 57.92 & 0.058 \\
\hline
\end{tabular}

a Total number of segregating sites.

b Average number of nucleotide differences between sequences; Tajima's estimate of the population mutation rate, $\theta$.

c Average number of nucleotide differences per site.

d Number of nonsynonymous sites.

e Average number of pairwise differences of nonsynonymous sites.

f Number of synonymous sites.

g Average number of pairwise differences of synonymous sites.

${ }^{\text {h }}$ Ratio of $\mathrm{dN} / \mathrm{dS}$.

i Positively selected amino acid position number and change.

j Watterson's estimate of the population mutation rate, $\theta$. 
occurred in only one Bertie County $2005 \mathrm{NC} 12 \mathrm{C}$ isolate and one Suffolk County 2007 NC12C isolate.

Identifying nonrecombining partitions using compatibility is suitable only when the mutation rate is significantly lower than the recombination rate (24), a condition violated by Tospovirus spp. (33). As expected, when examining site compatibility matrices for each locus, boundaries for partitions of distinct evolutionary history could not be discerned. Because certain statistical tests assume that no recombination is present in sequence data, incompatible sites were removed from each locus alignment when performing statistical tests for neutrality and population subdivision. The $\mathrm{N}$ gene had 47 incompatible sites removed, the NSm had 64 incompatible sites removed, and the RdRp had 112 incompatible sites removed.

Neutrality and population subdivision. The values for the Tajima's $D$, Fu and Li's $D^{*}$ and $F^{*}$, and Fu's $F_{\text {s }}$ test statistics were significant and negative (Table 4). Hudson's test statistics and Wright's $F_{\mathrm{ST}}$ indicated that the population was panmictic (Table $5)$. For all loci, the calculated value of Hudson's $S_{\mathrm{nn}}$ was close to 0.5 and not significant. Calculations of Wright's $F_{\mathrm{ST}}$ for the N, $\mathrm{NSm}$, and RdRp gene (a maximum value of 0.011 for both the $\mathrm{N}$ and NSm genes and 0.047 for the RdRp gene) indicated that the percentage of genetic differentiation accounting for the total amount of genetic variation did not exceed $4.7 \%$ in any comparison.

\section{DISCUSSION}

The objectives of this research were to characterize the genetic diversity and structure of TSWV sampled from a single crop in a local geographical area, and to determine whether global TSWV population diversity and structure reported previously (60) would be reflected in a population sampled on a smaller geographic scale. We found that the genetic diversity in the TSWV population from peanut in North Carolina and Virginia was lower and did not exhibit subdivision by geography compared with global populations of TSWV (60). Additional analysis of $\mathrm{N}$ gene sequences from representative isolates in this and the global study also indicated that our isolates clustered within the "southeastern clade" previously identified by Tsompana et al. (60), based on maximum parsimony and maximum likelihood analysis (data not shown). Our second objective was to investigate the evolutionary forces acting upon TSWV populations sampled from peanut in North Carolina and Virginia. We determined that mutation and purifying selection were the predominant evolutionary forces influencing the population structure of TSWV in peanut in North Carolina and Virginia but that there was also evidence for recombination, which was not found in global populations of TSWV (60).

We also provide evidence that identical specific sequences of TSWV can be sampled repeatedly from season to season. In general, isolate composition for each haplotype was not restricted by geographic area, year, or cultivar of peanut. The major haplotypes for the N and NSm loci were found in each geographic area in each sampled field season and in Sampson County after sampling for only one season. This pattern suggests that there are sequence regions of the genome that persist in the environment from season to season which could be facilitated by the numerous secondary host reservoirs that are known for TSWV (40) and perpetuated by recombination between different virus strains. This finding has important implications for disease management and the development of TSWV field resistance in cultivated crops.

Our haplotype analysis measured the number of haplotypes, their frequency and diversity, and genetic distances within and between sequences (20). According to Moury et al. (32), these three parameters are required to accurately measure the genetic diversity of a viral population (32). To calculate genetic distance, we used Tajima's calculations of $s$, the number of segregating sites, and $\pi$, the average number of nucleotide differences (56), because of a priori knowledge of the nonequilibrium state of the population (i.e., the occurrence of bottlenecks) $(27,28)$. The most appropriate estimate of the population mutation rate, $\theta$, for our data is Tajima's estimate, which is based on the average number of pairwise distances (54). Watterson's estimate of $\theta(64)$ is based upon the number of segregating sites, which is influenced by the size of the current population and can be inflated by the presence of numerous unique sequences (56), as is the case in our data: Watterson's estimates of $\theta$ were approximately five times greater than Tajima's estimate. This is supported by numerous recent mutations indicated in our data by significant values of the neutrality tests and frequent occurrence of singleton haplotypes. Our finding indicates that mutation is a significant effect in shaping the population structure of our TSWV.

The measures of haplotype diversity, Hd, can range from zero, meaning no diversity, to 1.000 , which indicates high levels of

TABLE 4. Summary of the number of compatible sites used and neutrality test statistic values for the nucleocapsid (N), movement (NSm), and RNA-dependent RNA polymerase (RdRp) loci of Tomato spotted wilt virus on peanut ${ }^{\mathrm{a}}$

\begin{tabular}{|c|c|c|c|c|c|}
\hline Gene & Compatible sites & Tajima's $D$ & Fu and Li's $D^{*}$ & Fu and Li's $F^{*}$ & Fu's $F_{\mathrm{s}}$ \\
\hline $\mathrm{N}$ & 673 & $-2.732 * *$ & $-7.183^{* *}$ & $-5.925 * *$ & $-20.614 * *$ \\
\hline NSm & 635 & $-2.739 * *$ & $-8.612 * *$ & $-6.776^{* *}$ & $-19.938 * *$ \\
\hline $\mathrm{RdRp}$ & 887 & $-2.766 * *$ & $-8.990 * *$ & $-6.966^{* *}$ & $-20.299 * *$ \\
\hline
\end{tabular}

${ }^{a}$ Asterisks (**) indicate a significant result $(P<0.001)$.

TABLE 5. Summary of subdivision test statistics $K_{\mathrm{S}}, K_{\mathrm{T}}, K_{\mathrm{ST}}$, and $S_{\mathrm{nn}}$ and the value of Wright's index $F_{\mathrm{ST}}$ for comparisons between geographical area of the nucleocapsid (N), movement (NSm), and RNA-dependent RNA polymerase (RdRp) loci of Tomato spotted wilt virus on peanut

\begin{tabular}{|c|c|c|c|c|c|c|c|}
\hline Gene, comparison ${ }^{\mathrm{a}}$ & $K_{\mathrm{S}}$ & $K_{\mathrm{T}}$ & $K_{\mathrm{ST}}$ & $P$ value & $S_{\mathrm{nn}}$ & $P$ value & $F_{\mathrm{ST}}$ \\
\hline \multicolumn{8}{|c|}{$\mathrm{N}(\mathrm{B}=88, \mathrm{~F}=59, \mathrm{M}=42)$} \\
\hline B vs. F & 1.909 & 1.908 & -0.000 & 0.568 & 0.520 & 0.444 & 0.003 \\
\hline B vs. M & 1.674 & 1.678 & 0.003 & 0.010 & 0.553 & 0.039 & 0.011 \\
\hline \multicolumn{8}{|c|}{$\operatorname{NSm}(B=87, F=61, M=42)$} \\
\hline B vs. F & 1.970 & 1.972 & 0.001 & 0.192 & 0.567 & 0.016 & 0.010 \\
\hline B vs. M & 1.718 & 1.719 & 0.000 & 0.354 & 0.502 & 0.628 & 0.011 \\
\hline Fvs. M & 2.060 & 2.061 & 0.000 & 0.390 & 0.564 & 0.376 & 0.009 \\
\hline B vs. M & 2.337 & 2.341 & 0.002 & 0.050 & 0.532 & 0.225 & 0.047 \\
\hline F vs. M & 2.964 & 2.966 & 0.001 & 0.300 & 0.572 & 0.177 & 0.035 \\
\hline
\end{tabular}

${ }^{a} \mathrm{~B}=$ Bertie County, NC; F = Suffolk County, VA; and M = Sampson County, NC. 
haplotype diversity (37). For all three loci examined, 1 major haplotype and $>100$ minor haplotypes were sampled from the population. For our data, Hd was 0.993 to 0.999 , indicating very high levels of diversity for each locus. These levels were similar to those estimated for global populations, which were 0.857 to 1 (60), which suggests that the particular host may not affect the haplotype diversity. In our data, the RdRp locus showed the most diversity, based on the number of haplotypes (e.g., 167 haplotypes from 183 isolates), their frequency in the population, and the estimates of genetic distance. Other studies of Tospovirus spp. have focused on the diversity of the $\mathrm{N}$ gene for strain identification $(12,14,38,39,51,72)$ or the NSs (11) but none have examined the $\mathrm{RdRp}$ region to measure its diversity. The $\mathrm{RdRp}$ functions as a polymerase in the infected plant cell (9) and, in our data, appears to be under the same amount of purifying selection as the $\mathrm{N}$ and NSm loci, based on data from the neutrality tests and values of $\omega$, the $\mathrm{dN} / \mathrm{dS}$ ratio. However, the RdRp gene may exhibit greater diversity because of the higher numbers of segregating sites associated with longer sequence reads, which increased the number of haplotypes when the data were collapsed. An interesting follow-up study would be to test whether the number of nucleotides examined influences haplotype diversity. These studies should also include noncoding regions of the TSWV genome to provide enhanced statistical analysis of the data (47).

We have provided evidence that the population of TSWV is panmictic across the coastal plain region of North Carolina and Virginia. We examined the data for the presence of subdivision in our study isolates through the use of Hudson's test statistics, PermtestK and $S_{\mathrm{nn}}$, and the index for Wright's $F_{\mathrm{ST}}(66)$. For our data, the value of the $S_{\mathrm{nn}}$ statistic depended on the presence of conflict from incompatible sites in the data set. When analyzing data without incompatible sites, the $S_{\text {nn }}$ value was closer to 0.5 , which indicated panmixia in the populations. In contrast, when incompatible sites were included in the analysis, the value was 0.6 to 0.9 , which suggested that the conflict influenced the subdivision results (data not shown). Because of this disparity, we further estimated $F_{\mathrm{ST}}$ as a measure of the genetic structure. In our analysis of data both with and without incompatible sites, the percentage of genetic differentiation accounting for the total amount of genetic variation was, at maximum, $15.4 \%$ (data not shown). Therefore, we concluded that the subdivision seen in our data was influenced by recombination heterogeneity occurring in geographic subpopulations and was not a function of subspecies divergence, as shown in global studies of TSWV (60).

Estimates of the population summary statistics were similar in value across all loci, which possibly could be explained by the ecology of the virus population and sampling from a limited geographic area and a single host. The level of nucleotide diversity of the $\mathrm{N}$ gene sampled from our population is similar to other $\mathrm{N}$ gene studies with Cucurbit yellow stunting disorder virus (0.002) and Sweet potato chlorotic stunt virus (0.006) (20). Nucleotide diversity calculations reported by Tsompana et al. (60) were higher for their sampled N (0.024) and NSm (0.030) genes of global populations of TSWV. This global collection would be expected to show higher diversity due to the wide range of sampling.

We showed that the population is experiencing strong purifying selection for each of the three genes, as has been shown in other TSWV studies (60). To further examine evolutionary forces acting on the populations of TSWV, four neutrality test statistics (Tajima's $D$, Fu and Li's $D^{*}$ and $F^{*}$, and Fu's $F_{\text {s }}$ ) were used in this study to examine the sequence data for departure from neutrality. All of the Tajima's $D$ test statistics were significant and negative, which is a strong indication that each of the three loci are experiencing population bottlenecks, where the population is severely limited by some factor and only a few sequences compose the new population (55). The biology of the thrips vector and its feeding habits could serve as a source of population bottle- necks, as could adaptation to a new host plant. Almost all $D^{*}$ and $F^{*}$ test statistics were significant and negative, which implies that background selection (18), in which strong purifying selection suppresses variation in linked regions, and rapid population growth have both occurred. Also, the large significant negative values of Fu's $F_{\mathrm{s}}$ suggest that both genetic hitchhiking, which can happen when linked alleles become more common through positive selection, and rapid population growth have occurred in the population. Fu's $F_{\mathrm{s}}$ is also an indicator of the presence of recombination (18), which is consistent with the results of the compatibility matrices and our conclusions from the subdivision testing. These results also support our conclusions of population growth from our examination of haplotype diversity and population summary statistics. However, the lack of population size constancy concluded from the neutrality tests and considerable intra- and interlocus rate heterogeneity prevented us from accurately estimating the magnitude of the exponential growth in our population.

As a further measure of selection, we calculated values for $\omega$, a comparison of synonymous to nonsynonymous nucleotide substitution rates. This comparison detects and measures the selective pressure on encoded proteins. We used the counting method of Yang and Nielson (70) that is implemented in PAML, which takes into account the transition/transversion rate bias and the codon frequency bias while counting sites and differences (70). This method of estimating the $\omega$ ratio has been shown to be the most reliable compared with other computations (69). For our data, the calculation of the $\omega$ ratio for each gene was $<1$, which indicates strong purifying selection acting on each locus (70), especially for the NSm gene. These results also support the conclusions from the neutrality tests of strong purifying selection acting on the loci. Although our calculated values of $\omega$ ratio for the $\mathrm{N}$ gene were lower than previous estimates of 0.221 published for TSWV (60), this could indicate that there is increased selection in a more localized population than might be seen on a global scale. There are a number of elements of the biology and ecology of TSWV that could possibly account for strong purifying selection, such as population bottlenecking through vector transmission and host compatibility.

Limited positive selection was identified in individual codons in the N, Nsm, and RdRp genes of TSWV against a background of predominant purifying selection for the entire coding region. The nonsynonymous changes that indicated positive selection occurred in isolates of cvs. NC12C, Perry, Brantley, NC_V11, and Gregory collected primarily in 2007 at all field locations. This could suggest host- or geographic-associated selection pressure, because the mutation is common across all cultivars and areas of the study. Tsompana et al. (60) found positive selection at sites 10,174 , and 255 in the $\mathrm{N}$ gene across different hosts and geographies, which further supports the idea that the amino-acid change may be related to host-specific or geographic effects. However, Tsompana et al. (60) did not find any evidence of positive selection in the NSm gene, whereas we found that approximately half of our isolates contained an amino-acid change exhibiting positive selection. This suggests that positive selection pressure was greatest on this site of this gene, which may be due to the NSm protein's role in cell-to-cell movement or host range determination. Although Tsompana et al. (60) did not examine the RdRp gene for positive selection, we found a single site. This gene had two different nonsynonymous changes at the same site: from $\mathrm{Q}$ to $\mathrm{R}$ or $\mathrm{K}$. It is interesting to note that the majority of the isolates exhibiting positive selection were collected from 2007. This may indicate that an environmental effect occurred during the 2007 field season, or an adaptation over time. Overall, these findings show that purifying selection is acting to preserve function of these genes, while positive selection may be working as the isolates adapt to environmental factors such as location and host. 
Recombination in genetic data can violate assumptions of certain analyses, leading to distortion or misinterpretation of the results. For instance, if recombination is not addressed, it can negatively impact parameter estimation by overestimation and lead to incorrect inferences $(3,43)$. Furthermore, an assumption of neutrality testing is that the data contain no recombination $(18,19,55)$, and recombination increases the power of Hudson's tests to detect subdivision (23). Because of this, we investigated whether recombination was present in the peanut TSWV populations. Although compatibility methods lack power in detecting nonrecombining partitions in sequences with high mutation rates, they are more powerful than phylogenetic-based methods in detecting recombination (42) and we were able to detect recombination in all three of our genes by examining incompatibility among sites. Although it is currently unknown when in the TSWV infection cycle that recombination may take place, most recombination in viruses is assumed to occur during replication in the host (20). The virus is transmitted by at least 10 species of thrips $(41,50,65)$ in a persistent and circulative manner and it also replicates in its vector $(61,66)$ and secondary weed hosts $(8,10)$. It has also been shown that TSWV can occupy plants at the same time as a closely related virus, Impatiens necrotic spot virus (21), and that reassortment does occur in the TSWV genome $(45,46)$. Because of its ecology, it appears that TSWV has numerous opportunities to exchange genetic information with other strains or other viruses. Therefore, further investigation of the occurrence and rate of recombination for this virus is critical to correctly infer phylogenetic relationships and estimate population summary statistics. Based on the results presented in this study, recombination appears to play a significant role in the evolution of the TSWV genome, and warrants a more comprehensive examination.

Future evolutionary studies should consider including other loci, such as the NSs, which has been shown to be a genesilencing protein (57), and G1/G2, which have both been shown to interact with thrips vector gut cells (35). Examining these genes under a similar sampling strategy could further elucidate important epidemiological patterns of the disease. It will also be critical to maintain a frequent collection of TSWV in the same localized areas to examine the range of evolutionary rates of heterochronous data in a single host, as has been done for other RNA plant viruses such as Rice yellow mottle virus $(16,17)$.

This study has shown that TSWV is a highly adaptable, expanding virus that plays an important role in commercial agriculture. Mutation generates diverse local populations of virus, creating a large pool of mutants from which new, stronger isolates can emerge. Recombination also appears to play a role in the evolution of this virus, and should be examined in more detail. By understanding the molecular population dynamics of TSWV, thrips, and their hosts, we can design better ways to control or prevent outbreaks, lessen the effects of resistance breaking, and ease the economic consequences of TSWV.

\section{LITERATURE CITED}

1. Adkins, S. 2000. Tomato spotted wilt virus-positive steps towards negative success. Mol. Plant Pathol. 1:151-157.

2. Adkins, S., Quadt, R., Choi, T., Ahlquist, P., and German, T. L. 1995. An RNA-dependent RNA polymerase activity associated with virions of Tomato spotted wilt virus, a plant- and insect-infecting Bunyavirus. Virology 207:308-311.

3. Awadalla, P. 2003. The evolutionary genomics of pathogen recombination. Nat. Rev. Genet. 4:50-60.

4. Aylor, D. L., Price, E. W., and Carbone, I. 2006. SNAP: Combine and Map modules for multilocus population genetic analysis. Bioinformatics 22:1399-1401.

5. Best, R. J. 1968. Tomato spotted wilt virus. Adv. Virus Res. 13:65-145.

6. Bowden, L. C., Price, E. W., and Carbone, I. SNAP Clade and Matrix. North Carolina State University, Department of Plant Pathology, Raleigh.

7. Carbone, I., Yir-Chung, L., Hillman, B. I., and Milgroom, M. G. 2004.
Recombination and migration of Cryphonectria hypovirus 1 as inferred from gene genealogies and the coalescent. Genetics 166:1611-1629.

8. Chamberlin, J. R., Culbreath, A. K., Todd, J. W., and Demski, J. W. 1993. Detection of Tomato spotted wilt virus in Tobacco thrips (Thysanoptera: Thripidae) overwintering in harvested peanut fields. J. Econ. Entomol. 86:40-45.

9. Chapman, E. J., Hilson, P., and German, T. L. 2003. Association of L protein and in vitro Tomato spotted wilt virus RNA-dependent RNA polymerase activity. Intervirology 46:177-181.

10. Chatzivassiliou, E. K., Peters, D., and Katis, N. I. 2007. The role of weeds in the spread of Tomato spotted wilt virus by Thrips tabaci (Thysanoptera: Thripidae) in tobacco crops. J. Phytopathol. 155:699-705.

11. Chen, T., Huang, C., Kuo, Y., Liu, F., Yuan, C., Hsu, H., and Yeh, S. 2006. Identification of common epitopes on a conserved region of NSs proteins among Tospoviruses of Watermelon silver mottle virus serogroup. Phytopathology 96:1296-1304.

12. Chiemsombat, P., Gajanandana, O., Warin, N., Hongprayoon, R., Bhunchoth, A., and Pongsapich, P. 2008. Biological and molecular characterization of Tospoviruses in Thailand. Arch. Virol. 153:571-577.

13. Culbreath, A. K., Todd, J. W., and Brown, S. L. 2003. Epidemiology and management of Tomato spotted wilt in peanut. Annu. Rev. Phytopathol. 41:53-75.

14. de Avila, A. C., de Haan, P., Kormelink, R., Resende, R. D. O., Goldbach, R. W., and Peters, D. 1993. Classification of Tospoviruses based on phylogeny of nucleoprotein gene sequences. J. Gen. Virol. 74:153-159.

15. de Haan, P., Wagemakers, L., Peters, D., and Goldbach, R. W. 1990. The S RNA segment of Tomato spotted wilt virus has an ambisense character. J. Gen. Virol. 71:1001-1007.

16. Fargette, D., Pinel, A., Abubakar, Z., Traoré, O., Brugidou, C., Fatogoma, S., Hébrard, E., Choisy, M., Séré, Y., Fauquet, C., and Konaté, G. 2004. Inferring the evolutionary history of Rice yellow mottle virus from genomic, phylogenetic, and phylogeographic studies. J. Virol. 78:32523261 .

17. Fargette, D., Pinel, A., Rakotomalala, M., Sangu, E., Traoré, O., Sereme, D., Sorho, F., Issaka, S., Hébrard, E., Séré, Y., Kanyeka, Z., and Konaté, G. 2008. Rice yellow mottle virus, an RNA plant virus, evolves as rapidly as most RNA animal viruses. J. Virol. 82:3584-3589.

18. Fu, Y. 1997. Statistical tests of neutrality of mutations against population growth, hitchhiking and background selection. Genetics 147:915-925.

19. Fu, Y., and Li, W. H. 1993. Statistical tests of neutrality of mutations. Genetics 133:693-709.

20. García-Arenal, F., Fraile, A., and Malpica, J. M. 2001. Variability and genetic structure of plant virus populations. Annu. Rev. Phytopathol. 39:157.

21. Hoffmann, K., Geske, S. M., and Moyer, J. W. 1998. Pathogenesis of Tomato spotted wilt virus in peanut plants dually infected with Peanut mottle virus. Plant Dis. 82:610-614.

22. Hudson, R. R. 2000. A new statistic for detecting genetic differentiation. Genetics 155:2011-2014.

23. Hudson, R. R., Boos, D. D., and Kaplan, N. L. 1992. A statistical test for detecting geographic subdivision. Mol. Biol. 9:138-151.

24. Hudson, R. R., and Kaplan, N. L. 1985. Statistical properties of the number of recombination events in the history of a sample of DNA sequences. Genetics 111:147-164.

25. Ie, T. S. 1970. Tomato spotted wilt virus. In: CMI/AAB Descriptions of Plant Viruses, no. 39. Commonwealth Mycological Institute and the Association of Applied Biologists.

26. Jakobsen, I. B., Wilson, S. R., and Easteal, S. 1997. The partition matrix: exploring variable phylogenetic signals along nucleotide sequence alignments. Mol. Biol. Evol. 14:474-484.

27. Kaye, A. C., Abad, J., Shew, B. B., Cubeta, M. A., and Moyer, J. W. 2006. Exploring the role of Tomato spotted wilt virus and soilborne fungi in yellowing syndrome of peanut. (Abstr.) Phytopathology 96:S59.

28. Kaye, A. C., Kennedy, G. G., Shew, B. B., Cubeta, M. A., and Moyer, J. W. 2008. Population genetic data analysis of Tomato spotted wilt virus on peanut in North Carolina and Virginia. (Abstr.) Phytopathology 98:S79.

29. Kormelink, R., de Haan, P., Meurs, C., Peters, D., and Goldbach, R. W. 1992. The nucleotide sequence of the M RNA segment of Tomato spotted wilt virus, a Bunyavirus with two ambisense RNA segments. J. Gen. Virol. 73:2795-2804.

30. Kormelink, R., Storms, M. M. H., van Lent, J., Peters, D., and Goldbach, R. W. 1994. Expression and subcellular location of the NSm protein of Tomato spotted wilt virus (TSWV), a putative viral movement protein. Virology 200:56-65.

31. Law, M. D., and Moyer, J. W. 1990. A tomato spotted wilt-like virus with a serologically distinct N protein. J. Gen. Virol. 71:933-938.

32. Moury, B., Desbiez, C., Jacquemond, M., and Lecoq, H. 2006. Genetic diversity of plant virus populations: Towards hypothesis testing in molecular epidemiology. Adv. Virus Res. 67:49-87. 
33. Moya, A., Elena, S. F., Bracho, A., Miralles, R., and Barrio, E. 2000. The evolution of RNA viruses: a population genetics view. Proc. Natl. Acad. Sci. USA 97:6967-6973.

34. Moyer, J. W. 2000. Tospoviruses. Pages 592-597 in: Encyclopedia of Microbiology. J. Lederberg, ed. Academic Press, San Diego, CA.

35. Nagata, T., Inoue-Nagata, A. K., Prins, M., Goldbach, R. W., and Peters, D. 2000. Impeded thrips transmission of defective Tomato spotted wilt virus isolates. Phytopathology 90:454-459.

36. Nei, M. 1987. Molecular Evolutionary Genetics. Columbia University Press, New York.

37. Nei, M., and Tajima, F. 1981. DNA polymorphism detectable by restriction endonucleases. Genetics 97:145-163.

38. Nischwitz, C., Pappu, H. R., Mullis, S. W., Sparks, A. N., Langston, D. R., Csinos, A. S., and Gitaitis, R. D. 2007. Phylogenetic analysis of Iris yellow spot virus isolates from onion (Allium cepa) in Georgia (USA) and Peru. J. Phytopathol. 155:531-535.

39. Pappu, H. R., du Toit, L. J., Schwartz, H. F., and Mohan, S. K. 2006. Sequence diversity of the nucleoprotein gene of Iris yellow spot virus (genus Tospovirus, family Bunyaviridae) isolates from the western region of the United States. Arch. Virol. 151:1015-1025.

40. Parrella, G., Gognalons, P., Gebre-Selassie, K., Vovlas, C., and Marchoux, G. 2003. An update of the host range of Tomato spotted wilt virus. J. Plant Pathol. 85:227-264.

41. Pittman, H. A. 1927. Spotted wilt of tomatoes. J. Counc. Sci. Ind. Res. 1:74-77.

42. Posada, D., and Crandall, K. A. 2001. Evaluation of methods for detecting recombination from DNA sequences: computer simulations. Proc. Natl. Acad. Sci. USA 98:13757-13762.

43. Posada, D., and Crandall, K. A. 2002. The effect of recombination on the accuracy of phylogeny estimation. J. Mol. Evol. 54:396-402.

44. Price, E. W., and Carbone, I. 2005. SNAP: workbench management tool for evolutionary population genetic analysis. Bioinformatics 21:402-404.

45. Qiu, W. P., Geske, S. M., Hickey, C. M., and Moyer, J. W. 1998. Tomato spotted wilt tospovirus genome reassortment and genome segmentspecific adaptation. Virology 244:186-194.

46. Qiu, W. P., and Moyer, J. W. 1999. Tomato spotted wilt tospovirus adapts to the TSWV $\mathrm{N}$ gene-derived resistance by genome reassortment. Phytopathology 89:575-582.

47. Rosenberg, N. A., and Nordborg, M. 2002. Genealogical trees, coalescent theory and the analysis of genetic polymorphisms. Nat. Rev. Genet. 3:380-390.

48. Rozas, J., Sánchez-Del Barrio, J. C., Messeguer, X., and Rozas, R. 2003. DnaSP, DNA polymorphism analyses by the coalescent and other methods. Bioinformatics 19:2496-2497.

49. Salzman, R. A., Hasegawa, P. M., Bressan, R. A., Fujita, T., and ZhuSalzman, K. 1999. An improved RNA isolation method for plant tissues containing high levels of phenolic compounds or carbohydrates. Plant Mol. Biol. Rep. 17:11-17.

50. Samuel, G., Bald, J. G., and Pittman, H. A. 1930. Investigations on "spotted wilt" of tomatoes, Australia. Commonw. Counc. Sci. Ind. Res. Bull. No. 44.

51. Singh, L., Hallan, V., Jabeen, N., Singh, A. K., Ram, R., Martin, D. P., and Zaidi, A. A. 2007. Coat protein gene diversity among Chrysanthemum virus $B$ isolates from India. Arch. Virol. 152:405-413.

52. Soellick, T., Uhrig, J. F., Bucher, G. L., Kellmann, J., and Schreier, P. H. 2000. The movement protein NSm of Tomato spotted wilt tospovirus (TSWV): RNA binding, interaction with the TSWV $\mathrm{N}$ protein, and identification of interacting plant proteins. Proc. Natl. Acad. Sci. USA 97:2373-2378

53. Storms, M. M. H., Kormelink, R., Peters, D., Van Lent, J. W. M., and Goldbach, R. W. 1995. The nonstructural NSm protein of Tomato spotted wilt virus induces tubular structures in plant and insect cells. Virology 214:485-493.

54. Tajima, F. 1983. Evolutionary relationship of DNA sequences in finite populations. Genetics 105:437-460.

55. Tajima, F. 1989. Statistical method for testing the neutral mutation hypothesis by DNA polymorphism. Genetics 123:585-595.

56. Tajima, F. 1989. The effect of change in population size on DNA polymorphism. Genetics 123:597-601.

57. Takeda, A., Sugiyama, K., Nagaro, H., Mori, M., Kaido, M., Mise, K., Tsuda, S., and Okuno, T. 2002. Identification of a novel RNA silencing suppressor, NSs protein of Tomato spotted wilt virus. FEBS J. 532:75-79.

58. Thompson, J. D., Higgins, D. G., and Gibson, T. J. 1994. CLUSTAL W: Improving the sensitivity of progressive multiple sequence alignment through sequence weighting, position-specific gap penalties and weight matrix choice. Nucleic Acids Res. 22:4673-4680.

59. Tsompana, M. 2004. Molecular evolution and population genetics of Tomato spotted wilt virus (TSWV). Ph.D. dissertation, North Carolina State University, Raleigh.

60. Tsompana, M., Abad, J., Purugganan, M., and Moyer, J. W. 2005. The molecular population genetics of the Tomato spotted wilt virus (TSWV) genome. Mol. Ecol. 14:53-66.

61. Ullman, D. E., German, T. L., Sherwood, J. L., Westcot, D. M., and Cantone, F. A. 1993. Tospovirus replication in insect vector cells: immunocytochemical evidence that the nonstructural protein encoded by the S RNA of Tomato spotted wilt tospovirus is present in thrips vector cells. Phytopathology 83:456-463.

62. Van den Bosch, F., Akudibilah, G., Seal, S., and Jeger, M. 2006. Host resistance and the evolutionary response of plant viruses. J. Appl. Ecol. 43:506-516

63. Van den Hurk, J., Tas, P. W. L., and Peters, D. 1977. The ribonucleic acid of Tomato spotted wilt virus. J. Gen. Virol. 36:81-91.

64. Watterson, G. A. 1975. On the number of segregating sites in genetical models without recombination. Theor. Popul. Biol. 7:256-276.

65. Whitfield, A. E., Ullman, D. E., and German, T. L. 2005. Tospovirusthrips interactions. Annu. Rev. Phytopathol. 43:459-489.

66. Wijkamp, I., van Lent, J., Kormelink, R., Goldbach, R. W., and Peters, D. 1993. Multiplication of Tomato spotted wilt virus in its insect vector, Frankliniella occidentalis. J. Gen. Virol. 74:341-349.

67. Wright, S. 1951. The genetical structure of populations. Ann. Eugenics 15:323-354.

68. Yang, Z. 2007. PAML 4: Phylogenetic analysis by maximum likelihood. Mol. Biol. Evol. 24:1586-1591.

69. Yang, Z., and Bielawski, J. P. 2000. Statistical methods for detecting molecular adaptation. Trends Ecol. Evol. 15:496-503.

70. Yang, Z., and Nielsen, R. 2000. Estimating synonymous and nonsynonymous substitution rates under realistic evolutionary models. Mol. Biol. Evol. 17:32-43.

71. Yang, Z., Wong, W. S., and Nielsen, R. 2005. Bayes Empirical Bayes inference of amino acid sites under positive selection. Mol. Biol. Evol. 22:1107-1118

72. Zheng, Y. X., Chen, C. C., Yang, C. J., Yeh, S., and Jan, F. J. 2008 Identification and characterization of a Tospovirus causing chlorotic ringspots on Phalaenopsis orchids. Eur. J. Plant Pathol. 120:199-209. 